\title{
Haemodynamic response to intravenous vasopressin and nitroglycerin in portal hypertension
}

\author{
D WESTABY, A GIMSON, P C HAYES, AND ROGER WILliAMS \\ From the Liver Unit, King's College School of Medicine and Dentistry, Denmark Hill, London
}

SUMMARY We have evaluated the haemodynamic effects of intravenous (iv) nitroglycerin (NG) and vasopressin (VP) alone and in combination, in 12 patients with cirrhosis and recent variceal haemorrhage (two to seven days). Nitroglycerin infusion alone $(200 \mu \mathrm{g} / \mathrm{min})$ produced a significant fall in portal pressure (WHVP-FHVP) (from $16 \cdot 4(0 \cdot 6)$ to $13 \cdot 3(1 \cdot 2) \mathrm{mmHg} ; \mathrm{p}<\cdot 001$ ) associated with hypotension (mean arterial pressure from $95(7)$ to $78(9) \mathrm{mmHg} ; \mathrm{p}<0.005)$. Vasopressin alone $(0.4$ IU/min) reduced portal pressure $(20.7(1.3)$ to $14.0(1.3) \mathrm{mmHg}$; $<0.001)$, but there was considerable variation in the systemic haemodynamic changes with increased cardiac output in four of six patients. The combination of vasopressin and nitroglycerin corrected all systemic haemodynamic disturbances produced by either agent alone. This combination led, however, to a further reduction in portal pressure (from $13.7(0.9)$ to $11.7(0.7) \mathrm{mmHg} \mathrm{p<0.01).} \mathrm{These} \mathrm{results} \mathrm{show} \mathrm{that:}$ (1) intravenous nitroglycerin reduces portal pressure, and (2) the combination of nitroglycerin and vasopressin reverses systemic haemodynamic disturbances produced by either agent alone and leads to a further decrease in portal pressure.

The therapeutic efficacy of a vasopressin (VP) infusion is restricted by complications associated with systemic vasoconstriction, which include ischaemia and infarction of the myocardium, gastrointestinal tract, and skin. These complications require cessation of therapy in up to $17 \%$ of cases and are fatal in $3 \% .^{\prime}$ Recent studies have shown that the addition of sublingual nitroglycerin (NG) reverses the systemic haemodynamic disturbances of vasopressin ${ }^{2}$ whilst maintaining the reduction in portal pressure. When there is active variceal bleeding the intravenous infusion of nitroglycerin has the advantages of offering more reliable drug administration whilst allowing the dose to be varied in response to changes in systemic haemodynamics.

The aim of the present study was to investigate the systemic and portal haemodynamic effects of intravenous nitroglycerin and vasopressin, alone and in combination, in patients with cirrhosis and recent variceal bleeding.

Address for correspondence: Dr Roger Williams, Liver Unit, King's College Hospital School of Medicine and Dentistry, Denmark Hill, London SE9 8RX. Received for publication 4 September 1987.
Methods

\section{PATIENTS}

Twelve patients (nine men and three women) with a mean age of 52.7 (2.3) years; mean (SE) with biopsy proven cirrhosis (eight alcoholic, two primary biliary and one each of chronic active hepatitis and cryptogenic cirrhosis) were studied within two to seven days of variceal haemorrhage. No acute bleeding had recurred within at least 48 hours before the study. The severity of the underlying liver disease as graded by the Pugh Classification ${ }^{3}$ showed nine patients to be of grade $\mathrm{B}$ and three of grade $\mathrm{C}$. None had previous history of cardiac disease.

After an overnight fast an hepatic venous balloon occlusion catheter ${ }^{4}$ was introduced through the femoral vein and a flow directed pulmonary artery thermodilution ${ }^{5}$ catheter was inserted through the subclavian vein. In both cases the midaxillary line was used as the external zero reference. Measurements were taken of heart rate, cardiac output (CO), pulmonary capillary wedge pressure (PCWP), pulmonary artery pressure (PAP), right atrial pressure (RAP), arterial blood pressure by sphygmomano- 
metry, wedged hepatic venous pressure (WHVP) and free hepatic venous pressure (FHVP) before, 15 minutes after initial infusion and after 15 minutes of a combined infusion. From these measurements the following derived variables were obtained:

Portal pressure gradient $(\mathrm{PPG}=\mathrm{WHVP}-\mathrm{FHVP})$;

Systemic vascular resistance index $(\mathrm{SVRI})=$

$$
\frac{(\mathrm{MAP}-\mathrm{RAP})}{\mathrm{CI}} \times 79 \text { and }
$$

Left ventricular stroke work index (LVSWI)=

$$
\frac{\mathrm{CI} \times \text { MAP }}{\mathrm{HR}}
$$

Patients were randomly allocated to receive vasopressin or nitroglycerin as the initial infusion followed by the addition of the second agent. Vasopressin was given as a bolus of $10 \mathrm{IU}$ followed by 0.4 $\mathrm{IU} / \mathrm{min}$. Nitroglycerin was infused at a dose of 200 $\mu \mathrm{g} / \mathrm{min}$ after an initial bolus of $1000 \mu \mathrm{g}$.

Informed consent was requested and obtained from the patients included in this study, all of whom had previously received the two drugs as treatment for an episode of active variceal bleeding. The study was approved by the Ethical Committee of King's College Hospital.

\section{STATISTICAL ANALYSIS}

All results are given as mean (SE) and compared using the paired Student's $t$ test.

\section{Results}

Nitroglycerin (Table 1a, Fig. 1)

The infusion was followed by a significant fall in mean arterial pressure (MAP) (from 95 (7) to 79 (9) $\mathrm{mmHg} ; \mathrm{p}<0.005$ ) and cardiac index (from 4.11 (0.62) to $\left.3.29(0.4) 1 / \mathrm{min}_{-1} / \mathrm{m}_{-2} ; \mathrm{p}<0.005\right)$. Although the right atrial pressure fell (from $7.7(0.9)$ to $5.2(1.3$ $\mathrm{mmHg} ; \mathrm{p}<0.02)$ there was no fall in free hepatic venous pressure whilst there were significant reductions in both wedged hepatic venous pressure $(28.7(1.6)$ to $25.8(1.8) \mathrm{mmHg} ; \mathrm{p}<0.005)$ and portal pressure gradient (from 16.4 (0.6) to $13.3(1.2)$ $\mathrm{mmHg} ; \mathrm{p}<0 \cdot 01)$. Left ventricular stroke work index fell (from 53 (9) to 33 (4) $\mathrm{gM} \mathrm{m}_{-2} \mathrm{bt}_{-1} ; \mathrm{p}<0.02$ ) whilst systemic vascular resistance index remained unchanged (from 1887 (224) to 1784 (326) dynes/ $\left.\mathrm{sec}_{-1} \mathrm{~cm}_{-5} \mathrm{~m}_{-2}\right)$.

vasopressin (Table 1b, Fig. 2)

The vasopressin infusion produced a wide range of haemodynamic responses. Whilst overall there was no significant change in mean arterial pressure, heart rate, and cardiac index it is of note that in four of the six patients an increase in cardiac index was observed. Pulmonary capillary wedge pressure and right sided heart pressure (right atrial pressure and pulmonary artery pressure) rose significantly. Portal pressure gradient fell (from $20.7(1.3)$ to $14.0(1 \cdot 3)$ $\mathrm{mmHg} ; \mathrm{p}<0.001)$ due to a reduction in wedged hepatic venous pressure (from $32.2(2.9)$ to 26.5 $(2.2) \mathrm{mmHg} ; \mathrm{p}<0.02)$ whilst the free hepatic venous pressure remained unchanged. The left ventricular stroke work index rose marginally and nonsignificantly (from 47 (7) to 50 (7) $\mathrm{gM} \mathrm{m}_{-2} \mathrm{bt}_{-1}$ ) whilst systemic vascular resistance index remained unchanged (from 1967 (230) to 1888 (206) dynes/ $\left.\mathrm{sec}_{-1} \mathrm{~cm}_{-5} \mathrm{~m}_{-2}\right)$.

COMBINED THERAPY (Tables $1 a, b)$

Irrespective of which drug was given first, the combination of the two drugs reversed the systemic haemodynamic changes of either drug alone (Figs. 1 and 2). In contrast, the combination of both drugs led to a further, significant, reduction in portal pressure gradient from $13.7(0.9)$ to $11.7(0.7) \mathrm{mmHg}$; $\mathrm{p}<0.01)$ irrespective of which drug was administered first. The left ventricular stroke index rose significantly when vasopressin was added to nitroglycerin (from 33 (4) to $50(5) \mathrm{gM} \mathrm{m}_{-2} \mathrm{bt}_{-1} ; \mathrm{p}<0 \cdot 005$ ) and fell when nitroglycerin was combined with vasopressin (from 50 (7) to 39 (6) $\mathrm{gM} \mathrm{m}_{-2} \mathrm{bt}_{-1} ; \mathrm{p}<0 \cdot 05$ ). The systemic vascular resistance index again remained unchanged.

\section{Discussion}

This study confirms that nitroglycerin when given intravenously is effective in reversing the systemic haemodynamic changes produced by vasopressin alone despite the wide range of responses observed with the latter. As already stated, intravenous nitroglycerin has a significant advantage over other routes of administration - for example, sublingual and transdermal, during active variceal bleeding. The mechanism(s) whereby nitroglycerin reverses the systemic haemodynamic disturbances are complex ${ }^{2}$ but is likely to be related to those changes observed when the drug is used alone. Previous studies in animals have shown that although nitrates affect both cardiac preload and afterload, changes in right atrial pressure, as manifestation of a reduction in preload, occur at a considerably lower dose. ${ }^{6}$ In this study the major effect of nitroglycerin was a reduction in cardiac index and right heart pressures consistent with a reduction in cardiac preload. Calculated systemic vascular resistance index did not fall significantly. These results would suggest that the reversal of systemic haemodynamic disturbances induced by vasopressin are the result of an effect of nitroglycerin 
Table 1a Effect of nitroglycerin alone and in combination with vasopressin on portal and systemic haemodynamics

\begin{tabular}{|c|c|c|c|c|c|c|c|}
\hline & & Baseline & & Nitroglycerin & & Nitroglycerin + & + Vasopressin \\
\hline & & & * & & $\dagger$ & & $\ddagger$ \\
\hline MAP & $(\mathrm{mmHg})$ & $95(7)$ & $(\mathrm{p}<0.005)$ & $79(9)$ & $(\mathrm{p}<0.05)$ & $94(7)$ & (NS) \\
\hline HR & $\left(\mathrm{bt} / \mathrm{min}_{-1}\right)$ & $84(6)$ & (NS) & $97(9)$ & $(\mathrm{p}<0.02)$ & $75(8)$ & (NS) \\
\hline $\mathrm{CI}$ & $\left(\mathrm{L} \mathrm{min}_{-1} \mathrm{~m}_{-2}\right)$ & $4 \cdot 11(0.62)$ & $(p<0.05)$ & $3.29(0.4)$ & (NS) & $3.74(0.5)$ & (NS) \\
\hline RAP & $(\mathrm{mmHg})$ & $7 \cdot 7(0.9)$ & $(\mathrm{p}<0.02)$ & $5 \cdot 2(1 \cdot 3)$ & (NS) & $7 \cdot 4(1 \cdot 3)$ & (NS) \\
\hline PAP & $(\mathrm{mmHg})$ & $16 \cdot 6(1 \cdot 5)$ & $(\mathrm{p}<0.02)$ & $11 \cdot 9(1 \cdot 1)$ & (NS) & $15 \cdot 9(1 \cdot 3)$ & (NS) \\
\hline PCWP & $(\mathrm{mmHg})$ & $10 \cdot 0(0 \cdot 6)$ & (NS) & $7 \cdot 1(1 \cdot 4)$ & (NS) & $11.5(2.0)$ & (NS) \\
\hline FHVP & $(\mathrm{mmHg})$ & $12 \cdot 1(1 \cdot 8)$ & (NS) & $12 \cdot 4(1 \cdot 7)$ & (NS) & $12 \cdot 6(0.9)$ & (NS) \\
\hline WHVP & $(\mathrm{mmHg})$ & $28 \cdot 7(1.6)$ & $(\mathrm{p}<0.005)$ & $25.8(1 \cdot 8)$ & (NS) & $24.4(1.6)$ & $(\mathrm{p}<0.05)$ \\
\hline PPG & $(\mathrm{mmHg})$ & $16.4(0.6)$ & $(\mathrm{p}<0.01)$ & $13 \cdot 3(1 \cdot 2)$ & (NS) & $11 \cdot 6(1 \cdot 2)$ & $(\mathrm{p}<0.005)$ \\
\hline LVSWI & $\mathrm{I}\left(\mathrm{gM} \mathrm{m}_{-2} \mathrm{bt}_{-1}\right)$ & $53(9)$ & $(\mathrm{p}<0.02)$ & $33(4)$ & $(\mathrm{p}<0.005)$ & $50(5)$ & (NS) \\
\hline SVRI & (dynes/sec $\mathrm{sem}_{-5} \mathrm{~m}_{-2}$ ) & $1887(244)$ & (NS) & $1784(326)$ & (NS) & $1856(282)$ & (NS) \\
\hline
\end{tabular}

$(N S)=$ not significant; $p$ values: ${ }^{*} \mathrm{NG} v$ baseline; $\uparrow \mathrm{NG}+\mathrm{VP} v \mathrm{NG} ; \ddagger \mathrm{NG}+\mathrm{VP} v$ baseline

Abbreviations: $\mathrm{MAP}=$ mean arterial pressure; $\mathrm{HR}=$ heart rate $\mathrm{CI}=$ cardiac index $; \mathrm{RAP}=$ right atrial pressure; $\mathrm{PAP}=$ pulmonary artery pressure $; \mathrm{PCWP}=$ pulmonary capillary wedge pressure $; \mathrm{FHVP}=$ free hepatic venous pressure; $\mathrm{WHVP}=$ wedged hepatic venous pressure; $\mathrm{PPG}=$ portal pressure gradient; $\mathrm{LVSWI}=$ left ventricular stroke index; $\mathrm{SVRI}=$ systemic vascular resistance index.
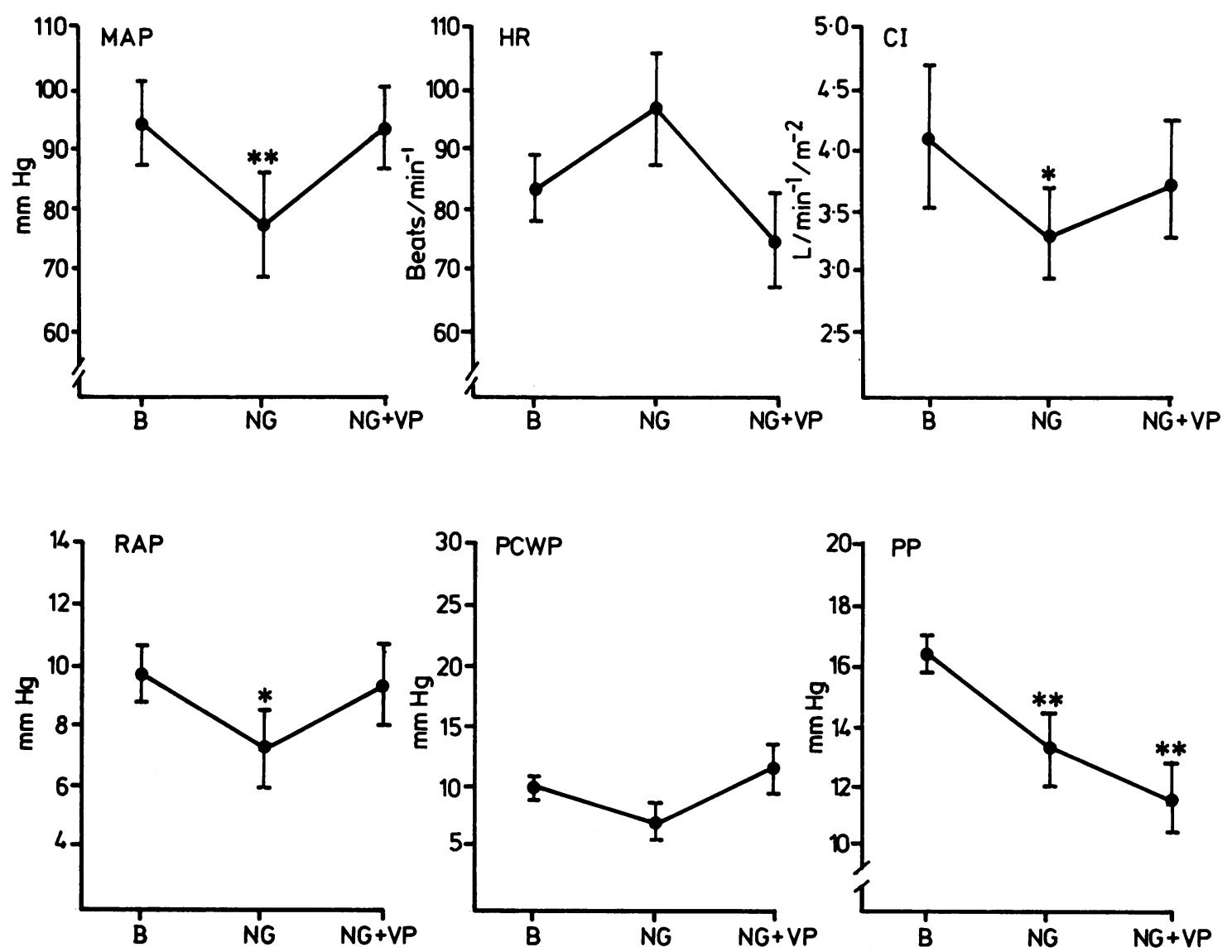

Fig. 1 Haemodynamic parameters before $(B)$ and after nitroglycerin $(N G)$ and nitroglycerin and vasopressin $(N G+V P)$. 
Table 1b Effect of vasopressin alone and in combination with nitroglycerin on portal and systemic haemodynamics

\begin{tabular}{|c|c|c|c|c|c|c|c|}
\hline & & Baseline & & vasopressin & & Vasopressin $+I$ & Nitroglycerin \\
\hline & & & * & & $\dagger$ & & $\ddagger$ \\
\hline MAP & $(\mathrm{mmHg})$ & $89(6)$ & (NS) & $92(7)$ & $(\mathrm{p}<0.02)$ & $81(6)$ & $(p<0.01)$ \\
\hline HR & $\left(\mathrm{bt} / \mathrm{min}_{-1}\right)$ & $85(4)$ & (NS) & $79(2)$ & $(\mathrm{p}<0.02)$ & $90(5)$ & (NS) \\
\hline & $\left(\mathrm{L} \min _{-1} \mathrm{~m}_{-2}\right)$ & $3.54(0 \cdot 30)$ & (NS) & $3.64(0.34)$ & (NS) & $3 \cdot 32(0 \cdot 31)$ & (NS) \\
\hline RAP & $(\mathrm{mmHg})$ & $5 \cdot 8(1.4)$ & $(p<0.05)$ & $8.3(1.7)$ & $(p<0.01)$ & $4 \cdot 7(1 \cdot 2)$ & (NS) \\
\hline PAP & $(\mathrm{mmHg})$ & $17 \cdot 0(4 \cdot 8)$ & $(\mathrm{p}<0.05)$ & $21 \cdot 3(5 \cdot 3)$ & $(\mathrm{p}<0.02)$ & $14 \cdot 7(4 \cdot 1)$ & (NS) \\
\hline PCWP & $(\mathrm{mmHg})$ & $8 \cdot 0(1 \cdot 6)$ & $(p<0.01)$ & $13.5(1 \cdot 2)$ & $(\mathrm{p}<0.01)$ & $7 \cdot 8(0 \cdot 4)$ & (NS) \\
\hline FHVP & $(\mathrm{mmHg})$ & $11 \cdot 5(2 \cdot 6)$ & (NS) & $12 \cdot 5(2 \cdot 0)$ & (NS) & $11 \cdot 7(2 \cdot 7)$ & (NS) \\
\hline WHVP & $(\mathrm{mmHg})$ & $32 \cdot 2(2.9)$ & $(p<0.02)$ & $26.5(2 \cdot 2)$ & $(p<0.05)$ & $23 \cdot 5(2 \cdot 2)$ & $(\mathrm{p}<0.005)$ \\
\hline PPG & $(\mathrm{mmHg})$ & $20 \cdot 7(1.3)$ & $(\mathrm{p}<0.001)$ & $14 \cdot 0(1 \cdot 3)$ & (NS) & $11 \cdot 8(0.9)$ & $(p<0.01)$ \\
\hline LVSWI & $\mathrm{I}\left(\mathrm{gM} \mathrm{m}_{-2} \mathrm{bt}_{-1}\right)$ & $47(7)$ & (NS) & $50(7)$ & $(\mathrm{p}<0.05)$ & $39(6)$ & (NS) \\
\hline SVRI & (dynes/sec $\mathrm{sec}_{-1} \mathrm{~cm}_{-5} \mathrm{~m}_{-2}$ ) & $1967(230)$ & (NS) & $1888(206)$ & (NS) & $1900(189)$ & (NS) \\
\hline
\end{tabular}

(NS)= not significant; $p$ values: ${ }^{*} \mathrm{VP} v$ baseline; $+\mathrm{VP}+\mathrm{NG} v \mathrm{VP} ; \ddagger \mathrm{VP}+\mathrm{NG} v$ baseline.

Abbreviations: $\mathrm{MAP}=$ mean arterial pressure; $\mathrm{HR}=$ heart rate; $\mathrm{CI}=$ cardiac index $; \mathrm{RAP}=$ right atrial pressure; $\mathrm{PAP}=$ pulmonary artery pressure; $\mathrm{PCWP}=$ pulmonary capillary wedge pressure; $\mathrm{FHVP}=$ free hepatic venous pressure; $\mathrm{WHVP}=$ wedged hepatic venous pressure; PPG = portal pressure gradient; $L V S W I=$ left ventricular stroke index; SVRI =systemic vascular resistance index.
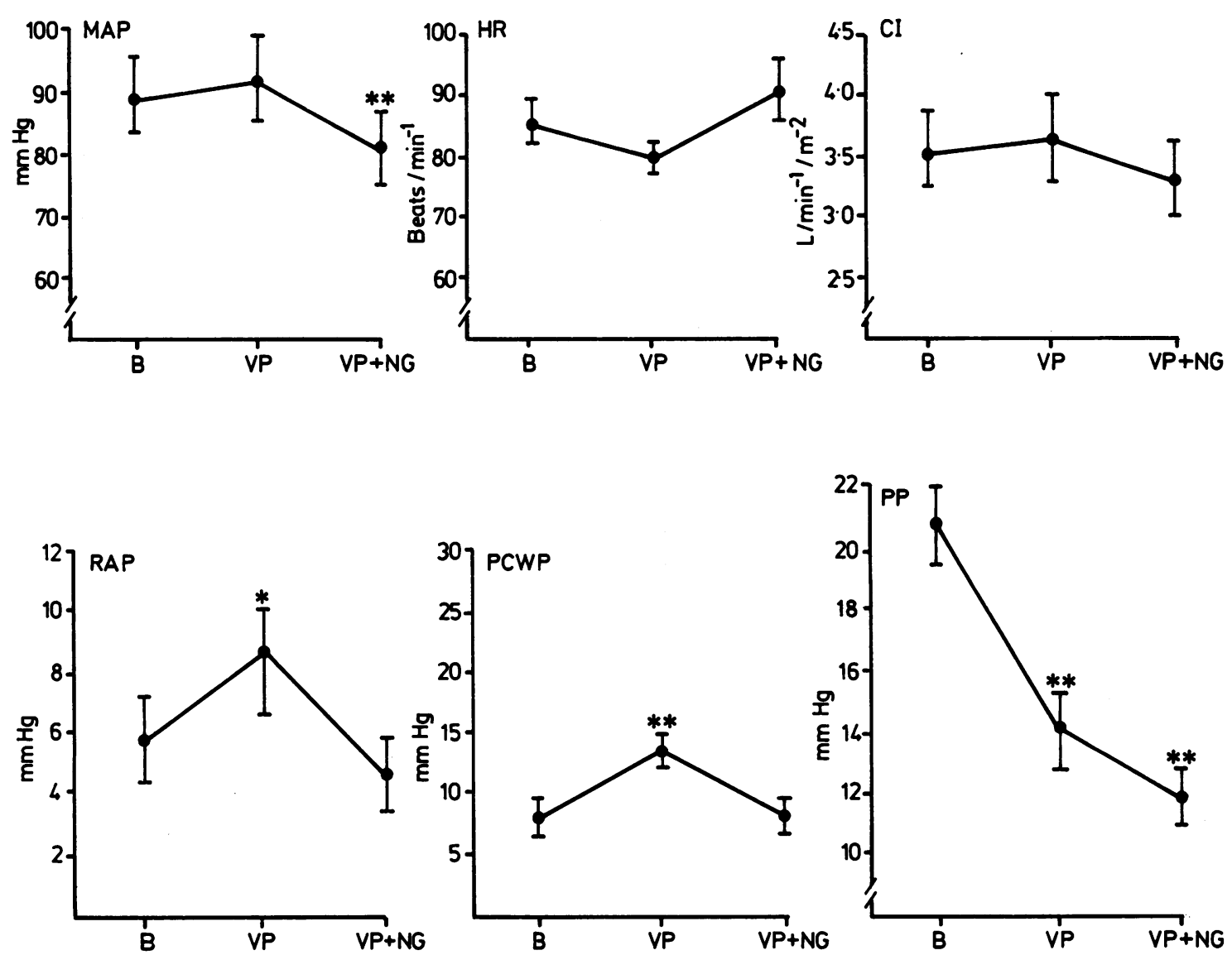

Fig. 2 Haemodynamic parameters before $(B)$ and after vasopressin $(V P)$ and vasopressin and nitroglycerin $(V P+N G)$. 
on preload rather than afterload. This is supported by the observation that systemic vascular resistance index did not change when the two drugs were combined, whereas right atrial pressure and pulmonary capillary wedge pressure returned to baseline.

The effect of intravenous nitroglycerin on portal pressure in man has not been previously investigated. The observed fall in portal pressure in this study may be explained by several mechanisms which include portal vein dilatation ${ }^{2}$ and a baroreceptor mediated splanchnic vasocontriction due to a fall in systemic blood pressure. ${ }^{7}$ Our data cannot differentiate between these two possibilities but the reduction in mean arterial pressure when nitroglycerin was given alone and when added to vasopressin is consistent with the latter. It follows from this that the additive effect of the two drugs on portal pressure gradient may be caused by splanchnic vasoconstriction mediated directly by vasopressin and reflexly by a nitroglycerin-induced reduction in blood pressure.

The effects of vasopressin upon systemic haemodynamics deserves comment. There was no observed increase in arterial pressure or systemic vascular resistance with this drug which is in contrast with the generally accepted response. ${ }^{2}$ In every case, however, the prompt appearance of pallor confirms a vasoconstrictor effect upon the skin and the reduction in portal pressure gradient provides evidence of splanchnic vasoconstriction. In such circumstances the failure of systemic vascular resistance to rise might be explained by a selective vasoconstrictor action of vasopressin with redistribution of blood flow to other vascular beds. The absence of a rise in arterial pressure with vasopressin has been observed by others when this was administered, as part of a controlled study, in patients with active variceal haemorrhage. ${ }^{8}$ In the present study four of the six patients receiving vasopressin initially showed an increase in cardiac index, a further effect seldom referred to, but which has been previously documented. ${ }^{9}$ The most likely explanation for this is an increase in venous return in response to reduced splanchnic pooling (secondary to splanchnic vasoconstriction). The pattern of the observed systemic haemodynamic changes in this study may reflect the patients studied - that is, advanced liver disease (Pugh Grade B and C) with recent variceal haemorrhage. We believe, however, that these observations may be more relevant to the setting of active variceal bleeding than haemodynamic studies carried out in well compensated patients.

It seems unlikely that the systemic haemodynamic changes seen with vasopressin in this study account for the cardiac complications observed in its clinical use. Direct coronary artery vasoconstriction may be a more important factor in their pathogenesis. A possible mechanism by which the addition of nitroglycerin might reduce the risk of such complications is by its effect upon left ventricular stroke index which was shown to fall significantly in the present study, as would also myocardial oxygen requirements. In clinical practice, a recently reported controlled trial from this Unit, has provided support for a beneficial effect of the addition of nitroglycerin upon the cardiac complications of a vasopressin infusion. ${ }^{10}$ The present haemodynamic study does not provide evidence that the combined infusion will reduce the infrequent but serious non-cardiac side effects such as gut and skin ischaemia.

Finally, it should be appreciated that nitroglycerin, by reducing cardiac preload and cardiac output, may be hazardous in hypovolaemic patients and is unlikely to be useful as a single agent in active variceal bleeding. Because of this risk of hypotension with nitroglycerin we advocate that the vasopressin bolus is initiated approximately one to two minutes before starting the nitroglycerin infusion and the intravenous administration of the latter thus provides the facility for titrating the dose against the systemic blood pressure. ${ }^{4}$

We would like to thank Ms Ann Pucknell for expert technical assistance.

\section{References}

1 Conn HO. A plethora of therapies. In: Westaby D, Macdougall B, Williams R, eds. Variceal bleeding. London: Pitman Medical, 1982: 221-52.

2 Groszmann RJ, Kravetz D, Bosch J, et al. Nitroglycerin improves the haemodynamic response of vasopressin in portal hypertension. Hepatology 1982; 2: 757-62.

3 Pugh RNH, Murray-Lyon IM, Dawson JL, Piretroni MC, Williams R. Transection of the oesophagus for bleeding oesophageal varices. BrJ Surg 1973; 60: 646-9.

4 Myers J, Taylor W. An estimation of portal venous pressure by occlusion catheterisation of an hepatic vein. J Clin Invest 1951; 30: 662-3.

5 Forrester JS, Ganz W, Diamond G, et al. Thermodilution cardiac output determination with a single flow direction catheter. Am Heart J 1972; 83: 306-11.

6 Bessenge E, Holtz J, Kinadeter H, Kolin A. Threshold dosages of nitroglycerin for coronary artery dilatation, afterload reduction and venus pooling in conscious dogs. In: Lichtlen PR, Engel H-J, Schrey A, Swan HJC, eds. Nitrates III. Berlin: Springer, 1981: 238-50.

7 Kroeger RJ, Groszman RJ. The effect of the combination of nitroglycerin and propranolol or splanchnic and systemic haemodynamics in a portal hypertensive rate model. Hepatology 1985; 5: 425-30.

8 Fogel MR, Knauer CM, Andres LL, et al. Continuous intravenous vasopressin in active upper gastrointestinal 
bleeding. A placebo-controlled trial. Ann Intern Med 1982; 96: 656-69.

9 Chandler JG. Vasopressin and splanchnic shunting: a quantitative comparison. Ann Surg 1982; 195: 543-53.
10 Gimson AES, Westaby D, Hegarty J, Watson A, Williams R. A randomised trial of vasopressin and vasopressin plus nitroglycerin in the control of acute variceal haemorrhage. Hepatology 1986; 6: 406-9. 